\title{
The Capabilities Approach and Measurement: The Influence of Human Capabilities on Student Academic Achievement - A Case Study in South Africa
}

\author{
Anesu Ruswa \\ Delson Chikobvu \\ Melanie Walker \\ University of the Free State \\ Email: anesuruswa@yahoo.co.uk
}

Doi:10.5901/mjss.2014.v5n23p1139

\begin{abstract}
This research was conducted to examine the influence of human capabilities on the academic performance of students within a South African institution of higher education. A total of 1503 students participated in a questionnaire survey. The findings illustrate the influences of measures of various human capabilities on academic performance. The over-arching hypothesis that student performance is dependent the 'real' freedoms a student has was tested through a statistical method. Ordinal Least Squares Regression was used to identify model estimates and its pragmatism was examined. The academic achievement is used as a proxy for wellbeing which in turn is influenced by various human capabilities. In this population of University students, out of a total of 10 human capabilities consiredered, the following capabilities were found to be statistically significant and hence deemed critical for the wellbeing (academic achievement) of students, educational resilience, learning disposion, bodily health and practical reasoning.
\end{abstract}

Keywords: capabilities; functionings; regression; indicators; measurement; wellbeing/achievement

\section{Introduction}

The Well-being of students is a very important aspect to consider when making policies which affect students. Sarah C White posits that Wellbeing has three aspects which are relational, subjective and material dimensions (White, 2010). Classic economics in the main and welfare economics in particular have focused to a large extend on measuring wellbeing through the lenses of the material dimension. The most popular theory in classic economics of measuring wellbeing is the Utility or Utilitarian theory which measures wellbeing using happiness as proxy (Berridge, 2000). This theory however is critiqued by, among others, Amartya Sen, Sabina Alkere and Mozaffar Qizilbash (Qiziffar, 2008). The greatest weakness of the Utilitarian approach to welfare as cited is that it is one-dimensional and does not take into account the fact that there are many other aspects, besides happiness and advantage that contribute to wellbeing. The Utilitarian theory also backgrounds key human development ethos like freedom, justice and human rights in favor of the creation of capital and deepening of economic reservoirs.

Universities provide fertile ground where this theory is propagated and nurtured as is purported by Robert J. Barro and Jong-Wha Lee who argue that education is the main determinant of economic progress in any country as it creates a pool of human capital (Barro \& Lee, 2001). This common line of argument bears the shoaliness of the human capital theory in that it does not investigate fully the quality of the education offered and it does not offer students the ultimate freedom to be and do what they value since they have to fuel the human capital machinery.

Amartya Sen introduced the human Capability Approach as an alternative and more comprehensive evaluative framework of Well-being than the Utilitarian theory (Sen, 1985b). In this approach he defines 'Wellbeing' as freedom to be and to do what is most valuable to you (Sen, 1999). The Capability approach has a few core concepts which include capability, functioning and agency. These core concepts of the Capabilities Approach have been operationalized in various fields including Education. This study is situated in Higher Education seeks, among other objectives, to quantitatively interrogate the merits of the Capabilities Approach in explaining variations in student academic achievements. The works of researchers like Martha Nussbaum (Nussbaum, 2000), Melanie Walker (Walker, 2006) and Merridy Wilson-Strydom provide a bedrock for the theoretical framework employed. 


\section{The Capabilities Approach and Measurement}

\subsection{Theoretical Framework}

The Capability Approach is a normative evaluative framework and as such can be used to evaluate real freedoms (Comim, et al., 2008). The main empirical applications of the Capability Approach are in the fields of Economics, Health and Econometrics championed by mavens like Sabina Alkire, Flavio Comim, Mozaffar Qizibash, Paul Anand and Enrica Chiappero Martinetti among others. The approach is viewed in mainstream economics as an alternative Economic Welfare theory. Below is an outline of the core relationships in the Capability Approach as summarized by Thomas Wells in the Encyclopaedia of Philosophy (Wells, 2012)

\section{The Capabilities Approach}

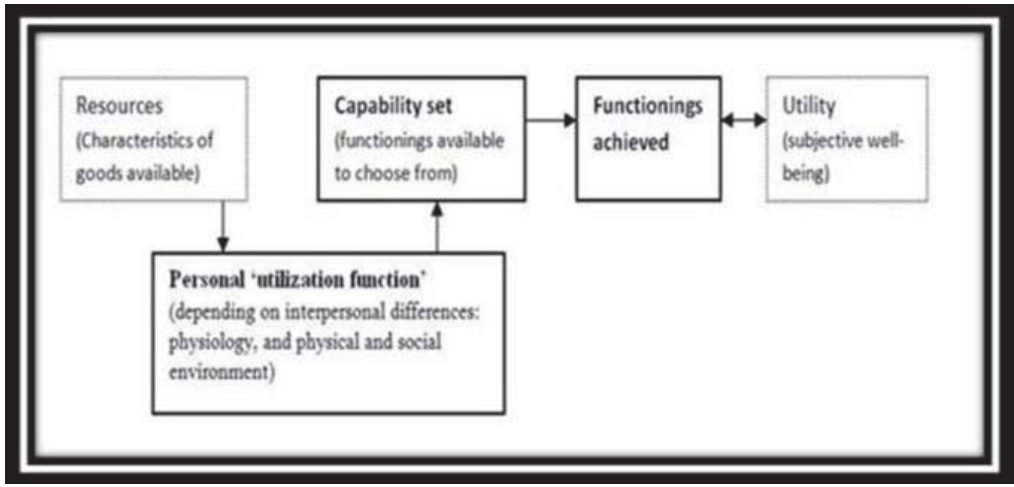

Figure 1: Outline of the core relationships in the Capability Approach

The core ideas of the Capability Approach are summarized in the table above. The Personal 'utilization function' in the table is conventionally referred to as to as Conversion Factors. Conversion factors are the social, environmental, economic and individual conditions or agents that facilitate the conversion of an individual's capabilities into functionings. Related to this is the issue of agency. The Capability approach encourages the expansion of an individual's agency/ choices in being what they value. A summary of the Theoretical Framework which I will use is given below:

\section{The Theoretical Framework}

Figure 2: Theoretical framework

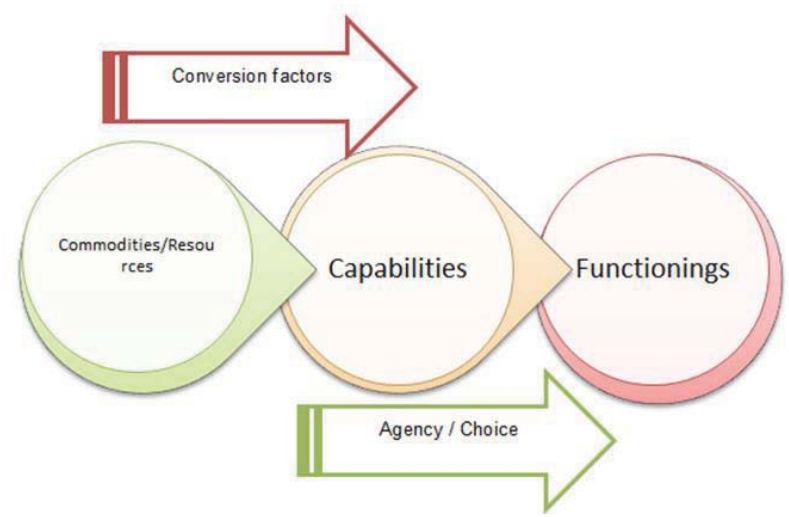

\subsection{The Capabilities set}

The measurement of capabilities was first hinted to by Sen in his 1985 monogram where he suggests an empirical approach to welfare economics diffrent from conventional methods. (Sen A. , 1985a). Previously most of the approaches 
used to evaluate welfare and wellbeing were from a Utilitarian perspective plied by the Human Capital Theory (Schokkaert \& Van Ootegem, 1990). These approaches looked at wellbeing or happiness as a bi-product of economic wellbeing and concluded that income and wellbeing had a positive correlation (Roemer, 1998).

Through the Capabilities Approach alluded to above, Sen identifies utility as the happiness derived from having a set of functionings where functionings are what a person manages to be and do (Basu, 1987). This complex view of functionings means that happiness is multi-dimensional and is as a result of a multiplicity or plurality of valued states of being and doing (Martinetti E. C., 2000). These valued states of being can be redacted into a set and measured. This set is referred to as the Capability set. Let ' $u$ ' be the set of valued functionings, Sen argues that the set can be represented as:

$$
\mathrm{u}=\mathrm{h}(\mathrm{f}(\mathrm{c}(\mathrm{x})) \ldots(\mathrm{i})
$$

where $h$ is a 'happiness' function (or any other suitable proxy of wellbeing) related to functionings achieved', $f$ is a function that maps goods characteristics onto functionings achieved, and $\mathrm{c}$ is a function that maps the consumer's bundle of goods onto a vector of characteristics. A key element of the capabilities approach both in Sen's original monograph and as it has developed is the distinction between functionings achieved - what a person is or does - and capabilities in the sense of the functionings that is feasible for a person to achieve (Sen A. , 1985a). Or as Basu puts it, functionings are what a person manages to be and do and thus they can be more easily analysed and measured than capabilities which are the real opportunities an individual has (Basu, 1987). To illustrate this concept, Sen introduces a set Q which is defined thus (Sen A., 1985a, p. 13):

$\mathrm{Q}=\{\mathrm{f}(\mathrm{c}(\mathrm{x}))\} \ldots$ (ii)

This is where the set of feasible functions is dependent on a person's own features and their entitlements to commodities. The personalisation of the set adds a new dimension of vantage over other Welfare theories. This then means the set $\mathrm{Q}$ is subjective to the individual. Paul Anand (Anand, Hunter, \& Smith, 2005b) defines Subjective Wellbeing (SWB) as the freedom a person has thus

$\mathrm{SWB}=\mathrm{g}(\mathrm{Q}) \ldots$ (iii)

Where $\mathrm{g}($.$) can be viewed as just a different 'happiness' function to \mathrm{h}($.$) The function defined above.$

Ferrer-i-Carbonel and Frijters in their 2004 paper (Ferrer-i-Carbonell \& Frjters, 2004) indicate that different individuals have different influencers of life satisfaction and thus cross-sectional personality data is more appropriate in measuring SWB as shown below:

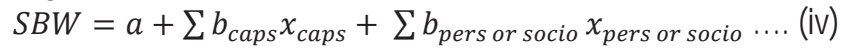

Where the subscript 'caps' denotes the capabilities indicators and the subscript 'pers or socio' denotes the person specific variables. Thus the individual's wellbeing function (SWB) takes into account the individual's agency and also models the individual's conversion factors. A pertinent proxy for SWB in the higher education context is academic achievement where academic achievement is synonymous with academic performance as reflected by marks.

\subsection{Methods of measuring}

\subsubsection{Factor analysis}

One of the most commonly used statistical methods in social science is factor analysis. There are two types of factor analysis: there is the Confirmatory Factor Analysis (CFA) and the Explanatory Factor Analysis (EFA) (LELLI, 2001). Generally, Factor analysis is used to ascertain relationships between variables and it starts with a correlation matrix for all individual variables. The algorithm initially assumes that only one underlying factor can adequately account for the association among variables, subtests, or items. In other words, it begins with the assumption that a one factor model can account for the correlations among item responses. To test this assumption, the algorithm must estimate the correlation between the underlying factor and each variable to determine if the correlation between the items is equivalent to the product of the path coefficients. The variable-total correlation can then be used as a proxy for the correlation between the observed items and the unobserved latent variable or factor. Furthermore, we can estimate what the correlation between variables should be if the one factor model fits the data using what we know about path diagrams and we can compare that to what the actual correlation between variables actually is (GUTTMAN, 1954).

Factor analysis is to create a smaller set of variables (the factors) that capture the original information nearly as well as the larger set of variables (the items). Some factor analytic methods, primarily those based on maximum likelihood estimation and confirmatory models use a statistical criterion which amounts to conducting an inferential test to determine whether the residual matrix contains an amount of co-variation that is statistically greater than zero (Filippone, Cheli, \& D'Agostino, 2001). If so the process continues until this is no longer the case, if not the process stops. 


\subsubsection{Fuzzy Set theory}

The Fuzzy set theory is a mathematical procedure introduced by Prof Lotfi A. Zadeh (Zadeh, 1965) to model and forecast the whole domain of mathematics which deals with imprecise information. Many argue that the approach has a lot of applications in different fields where uncertainty needs to be modelled. The theory has been applied in Engineering in the creation of various systems like the subway system and elevators. Von Altrock (Von Altrock, 1997) further led the application of the Fuzzy set theory in the fields of Business and Finance. This advent of business applications of the theory gave birth to a number of further applications in economics. Scholars like Chiappero, Lelli and Cheli-Lemmi applied the Fuzzy set theory to solve a number of economic problems around poverty reduction, social inequality and disadvantage (Chiappero, 2000; Lelli, 2001; Cheli \& Lemmi, 1995). These scholars used the theory in the Capabilities framework.

The Fuzzy theory functions on two levels; the first is a theoretical one where information is obtained from interviews with experts and other qualitative inquiries. The second involves a more mathematical interrogation. Addabbo et.al argues that the two approaches differ in that the latter does not require the history of the problem, but it relies on the experience of experts who have worked in the field for and the latter is based on past data and projects into the future the same structure of the past. The latter has a more econometric outlook than the former (Addabbo, Tommaso, \& Facchinetti, 2004).

\subsubsection{Structural Equation methods (SEM)}

SEM's were proposed by Zeller, Goldberger and Joreskog as a means to measure relationships between multiple and inter-related variables (Joreskog \& Goldberger, 1975; Zellner, 1970).

Most Social Science research uses Factor Analysis (Robeyns, THE CAPABILITY APPROACH IN PRACTICE, 2012) which is effective in showing correlation and causation but say nothing about the applicability of the model itself to the study (Lovell K, 1994). Structural Equation Modelling (SEM) however solves this problem and generally produces results which are richer in scope.

\subsubsection{Regression Analysis}

Regression analysis includes any statistical technique of modelling and analysing several variables, when the focus is on the relationship between a dependent (response) variable and one or more independent (explanatory) variables (Seber \& Lee, 2003). Regression analysis helps us understand how the typical value of the dependent variable changes when any one of the independent variables is varied, while the other independent variables are held fixed. Regression analysis is now the most widely used statistical technique, for example linear, regression to handle data with a linear relationship:

$$
y=\beta_{0}+\beta_{1} x_{1}+\beta_{2} x_{2}+\beta_{3} x_{3}+\cdots+\beta_{p} x_{p}+\varepsilon(v)
$$

Where $y$ is the dependent variable (the SWB in this case), $x_{i}$ is the independent (explanatory) variable (capability indicators), $\beta_{\mathrm{i}} \mathrm{s}$ are the model parameters, $\mathcal{E}$ is the random error term and $\mathrm{p}$ is the order of the multiple regression models.

The main aim of performing the regression analysis (Dielman, 1991) is to find out if:

1. The independent variable truly influences the dependent variable.

2. There is adequate fit of the data to the model.

3. The model adequately predicts responses.

The regression analysis approach will be applied in this paper.

\section{Methodology}

\subsection{The Data}

\subsubsection{Data source}

In the measurement of capabilities the most important step in to identify the capability set one is to work with. There are a number of ways to identify this set. Sen (1985a) argues in his monograph that the capability set for any group should be identified through a democratic process of public deliberation (Sen, 1985a). This transcendental view of public processes has been critiqued by scholars like Robeyns (2005) who argue that processes of public deliberation are seldom perfectly 
democratic as some elements in communities have more power and voice than others and more often than not, the outcomes of such processes reflect the views of just but a few powerful individuals (Robeyns, 2005). In as much as I agree with Sen that democratic deliberation is the ideal for selecting a capability set, I am appreciative of the fact that such processes are difficult to realize in actuality because of a number of confounding variables.

As such I am inclined to side with Martha Nussbaum (Nussbaum, 2003) provides a pragmatic solution to this conundrum by suggesting a universal list of capabilities. These capabilities she contends are reflective of the general capabilities that people value. The list contains ten core capabilities which she contends are a basis for all human capabilities. The debate about using predetermined lists of capabilities has been fierce in the capabilities circles though research has shown that the existing lists unremarkably capture most of the valuable capabilities. Renowned quantitative researchers like Sabina Alkire (Alkire, 2002) have interrogated Nussbaum's list together with over 39 other lists of capabilities and found a strong convergence in the capabilities identified thereby proving unequivocally that generic lists of capabilities are powerful instruments in capability studies.

Mozaffar Qizilbash (Qizilbash, 1996) echoes these sentiments by saying that there is large degree of similarity between the lists and they all point to Nussbaum's account as a general, high-level account of capabilities that public policy must address.

Taking into cognisance the above arguments, Nussbaum's list of capabilities was used as a backdrop for the capability set. As mentioned above, the study is situated in the higher education context so Nussbaum's list of core capabilities was augmented with a few capabilities which are germane to higher education suggested by Melanie Walker (Walker, 2006) and Merridy-Wilson Strydom (Wilson-Strydom, 2010b).

The following capabilities were identified as core capabilities in Higher Education:

- Educational Resilience- Defined as being able to navigate study, work and life. Being able to negotiate risk, to persevere academically, to be responsive to educational opportunities and adaptive constraints.

- Learning Disposition: Language, competence and confidence- Defined as being able to have curiosity and a desire for learning. Having confidence in one's ability to learn and being able to understand, read, write and speak confidently in the Language of instruction.

- Bodily Health- Defined as having the physical capacity to be and do what one values.

- Bodily Integrity - Defined as safety and freedom from all forms of physical and verbal harassment in the higher education environment.

- Senses, Imagination, and Thought- Defined as being able to use the senses, to imagine, think and reason and to do these things in a 'truly human' way, a way informed and cultivated by adequate education, including, but by no means limited to, literacy and basic mathematical and scientific training

- Emotions - Defined as being able to have attachments to things and people outside oneself.

- Practical reason - Being able to make well-reasoned, informed, critical, independent, intellectually acute, socially responsible, and reflective choices. Being able to construct a personal life project in an uncertain world. Having good judgment.

- Affiliation- Being able to participate in a group for learning, working with others to solve problems or tasks. Being able to work with others to form effective or good groups for collaborative and participatory learning. Being able to form good networks of friendship and belonging for learning support and leisure. Mutual trust.

- Leisure - Being able to laugh, to play, to enjoy recreational activities

- Control over one's environment- Being able to participate effectively in political choices that govern one's life; having the right of political participation, protections of free speech and association.

\subsubsection{Indicators of Capabilities}

Atkinson (2002) sheds light on what social indicators should both cover and how they are to be framed. Paul Anand (2006) further says in the creation of social indicators the concern should be in the existence of a normative justification as well as certain qualities of taxonomy particularly the diversity and comprehensiveness of its constituent elements.

Taking all that into account and using literature as a north-star, indicators for the selected capabilities were identified. The comprehensiveness and comprehensibility of these indicators was validated through rigorous inquiry by panels of different experts over a couple of months. 


\subsection{Measuring Instrument}

\subsubsection{Sampling}

The study was done at the Bloemfontein campus of the University of the Free in South Africa. The University of the Free State (UFS) was ideal because there is ethnical, racial and general demographic diversity in the student population. Further there are seven academic faculties, twenty-three on-campus residences, over sixty student-led and run societies and over twenty-four thousand three hundred and ninety-six students affiliated to its main campus. These dynamics make UFS a viable university to study student capabilities.

Yates (1949) gave an exposition of most of the classic sampling methods and concluded that Simple Random Sampling was the best sampling methods if the required outcome is a thoroughly representative sample (Yates, 1949).

To select our random sample, the whole population (24 296 students) was considered and presented with the measuring/data collecting instrument. A sufficiently large sample (1503) was obtained comprising of willing respondents.

Tanaka (1987) recommends a statistical method of finding the minimum sample size which can be sufficient for a given population (Tanaka, 1987). Thus, to get the minimum sample size $\mathrm{n}$ for a population of $\mathrm{N}=24396$ with a confidence level of $\mathrm{x} \%$ and a Margin of error of $\pm \mathrm{e}$ we use the following relationship:

$\mathrm{n}=\frac{\mathrm{Z}^{2} \cdot \mathrm{p} \cdot(1-\mathrm{p})}{\mathrm{e}^{2}}$ Or $\mathrm{n}=\left(\frac{\mathrm{z}_{1-\frac{\sigma}{2} \mathrm{x} \sigma}}{\mathrm{e}}\right)^{2} \ldots(\mathrm{vi})$

Where:

$\mathrm{Z}=\mathrm{Z}$ value from the normal table (e. g. 1.96 for $95 \%$ confidence level)

$\mathrm{p}=$ percentage picking a choice, expressed as decimal

$\mathrm{e}=$ confidence interval or margin of error, expressed as decimal (e. g. ,. $04= \pm 4$ )

Thus for a confidence Interval of $99 \%$ and a margin of error of 4 the minimum required sample size is 1040 . This means the sample is sufficiently large.

\subsubsection{The questionnaire}

There are a couple of instruments considered to obtain data for this study but none of them could work for the required sample size and the objectives of the study as well as a survey. Noting that there are various kinds of surveys, a crosssectional survey was chosen for this project. Blalock (1972) penned the advantages of cross-sectional surveys citing their usefulness in providing data for statistical research. He further notes that cross-sectional surveys provide valuable data in determining relationships, causality and correlations between variables.

Thus a survey was constructed based on the capability indicators. The survey had 89 questions and captured demographic as well as questions on the indicators of each capability. Of note, the survey also had a section where students could rank the capabilities according to the way they value them. There is also a section where students have to give a numeric indication of their wellbeing.

The questionnaire was revised and edited a couple of times by different adepts. There were 1503 respondents in total. The data was then coded and cleaned appropriately.

\subsection{Threshold Analyses: Data Transformation}

The greatest statistical violations occur when researchers using Structured Equation Modelling (SEM) and Regression Analysis to make necessary and accurate data to non-continuous data. These violations occur when numeric qualitative data is treated and handled as quantitative data. Scholars like K.A Bollen (Bollen, 1989) have been highlighting these violations but researchers still make them.

The primary data collected in this study is ordinal in scale as most of the questions were Likert-scale items. This then means the data needed to be transformed to continuous data i.e. quantitative data. To do this, a statistical method proposed by McKelvey and Zavoina called Threshold Analyses was employed (McKelvey \& Zavoina, 1975).

Most researchers capitalizes on the fact that ordinal variables have metric properties similar to continuous variables as noted by Flora and Curran (Flora \& Curran, 2004) and thus work with ordinal as if it is continuous. This relationship is highly spurious on the grounds that ordinal variables have no units of measurement and are not continuous and thereby not normally distributed. This then leads to a superfluity of conundrums as errors associated with heteroscedasticity begin to emerge. The solution therefore would be to transform the data using the Threshold analyses method in order to get accurate and informative covariance, mean matrices for the data and correlations (Joreskog, 
2002).

The threshold analyses are founded on the postulation that for each ordinal variable $T$, there exists an underlying continuous variable, $X^{*}$, in which $-\infty<X^{*}<\infty$. The latent continuous variable $\mathrm{X}^{*}$ represents the affect underlying the ordered responses which solves the problem of unequal weights for all the questions (Perakis, Maravelakis, Perakis, \& Xekalaki, 2005). The underlying distribution can be parameterized in two ways, either by standard parameterization e.g. the Standard Normal distribution with a mean of zero and a variance of 1 or using an alternative threshold method.

The alternative parameterization method is most suitable when using fixed or equal threshold analyses. With standard parameterization, all underlying variables are standardized to a mean of zero and a variance of one. When the choices are similar across a number of questions, the differences in the distributions of these variables are reflected in the differences in the means and variances of the underlying variables. Alternative parameterization makes use of these differences. Joreskog indicates that alternative parameterization is equivalent to standard parameterization, in that there is a one-to-one correspondence between the parameters resulting from each type of parameterization (Joreskog, 2002).

Referring to the Likert scale mentioned above, the possible response categories/thresholds are 'Disagree Strongly' (DS), 'Disagree' (D), 'Neutral (N), 'Agree' (A) and 'Agree Strongly' (AS). The ordinal variable X is mapped onto a continuous variable, $\mathrm{X}^{*}$ which reflects the study participant's degree of support for the target statement. In the research project, for the ordinal scale with five response choices, the observed $X$ is related to $X^{\star}$ according to the following measurement model:

$$
X=\left\{\begin{array}{lll}
1 \rightarrow D S & \text { if } & \tau_{0}=-\infty \leq X^{*}<\tau_{1} \\
2 \rightarrow D & \text { if } & \tau_{1} \leq X^{*}<\tau_{2} \\
3 \rightarrow N & \text { if } & \tau_{2} \leq X^{*}<\tau_{3} \\
4 \rightarrow A & \text { if } & \tau_{3} \leq X^{*}<\tau_{4} \\
5 \rightarrow A S & \text { if } & \tau_{4} \leq X^{*}<\tau_{5}=\infty
\end{array}\right.
$$
analyses.

The underlying continuous variables $X^{*}$, rather than the observed ordinal variables $X$, were thus used for the

Zuckerman argues that if ordinal variables are prime and irreducible then their natural sum is continuous (Zuckerman, 1971). Thus integrating this corollary and the Threshold method described above the natural sums of the coded ordinal variables were calculated and mapped back to the original capabilities they represent/indicate.

Ineluctably, out of the $65 \mathrm{X}$ variables we ended with $9 \mathrm{X}^{*}$ variables which are continuous in nature. These were then coded according to the capability sets they represent: learning disposition, Bodily health, Bodily integrity, senses and imagination, Emotions, Practical reason, Affiliation, Leisure and Control over one's environment.

\section{Results}

In-order to fully understand how the various capabilities affect student's marks the effect of some of the background variables was investigated as shown below. The background variables were not used in the final regression model as the aim was to investigate the influence of human capabilities as listed earlier.

\subsection{Demographics}

The average mark for the sample is $58 \%$. The average varies significantly across various demographical categories. The differences in the average Mark across gender, racial and residential lines shall be investigated below.

\subsubsection{Gender}

793 of the participants were females and 709 were male and the average marks were approximately $65 \%$ and $63 \%$ respectively. The graph below summarizes the differences. 


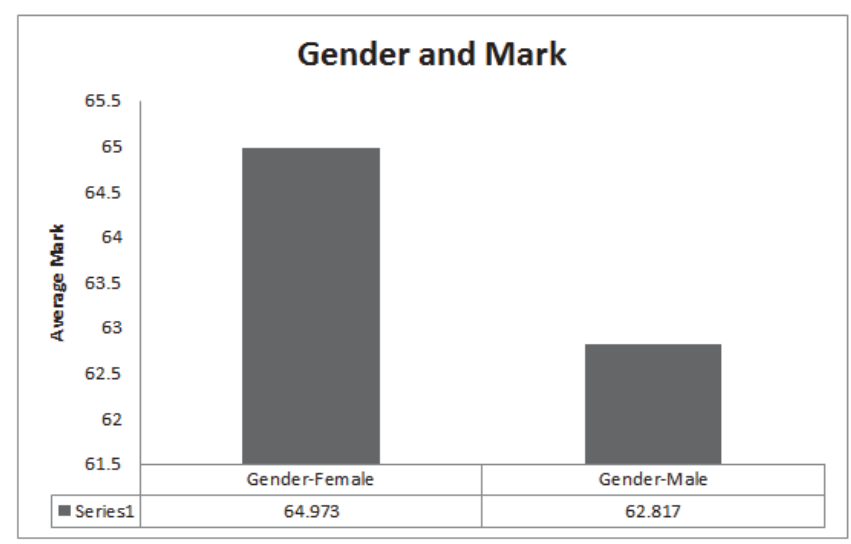

Figure 1: Gender and Mark

Testing the differences using Dunn-Sidak Multiple comparison test reveals the following:

Testing the hypotheses-

$H_{o}$ : There is no difference in the average Mark between different genders

$H_{1}$ : There is a difference in the avarage Mark between different genders

The following results are observed.

Table 2: Gender / Dunn-Sidak / Analysis of the differences between the categories with a confidence interval of 95\%:

\begin{tabular}{lccccc}
\hline Contrast & Difference & Standardized difference & Critical value & Pr > Diff & Significant \\
\hline Male vs. Female & 0.094 & 2.048 & 1.962 & 0.041 & Yes \\
Modified significance level: & & & 0.05 & & \\
\hline
\end{tabular}

Thus the null hypothesis is rejected at a significance level of $5 \%$ and it is concluded that there is a significant difference between the marks scored by females and those scored by males. The result implies female students generally performed slightly better than male students in this population.

\subsubsection{Residential status}

The effect of a student accommodation on the mark is important in identifying a comprehensive model. From the study $20.71 \%$ of the students who participated stay on-campus. The differences in the mark between on and off campus students are shown below:

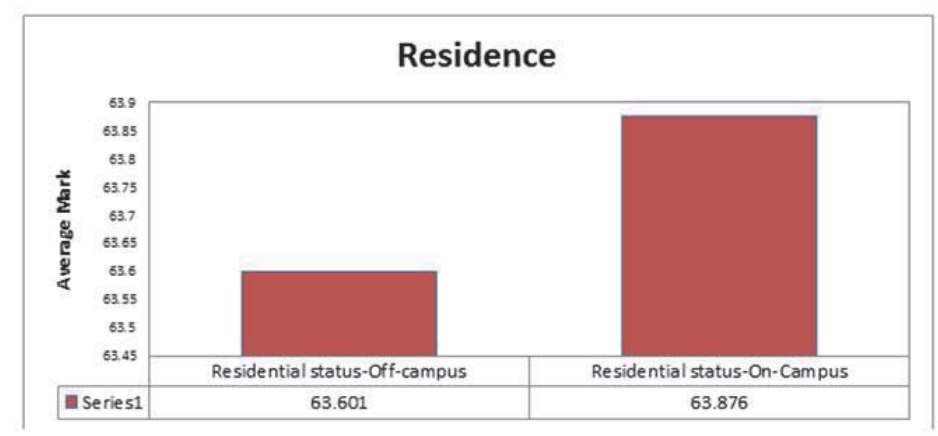

There appears to be a slight and negligible difference in the Marks between on and off-campus students but the DunnSidak test below shows that there is a significant difference between the marks and the residential status. Thus staying on-campus has a slight positive effect on academic performance. The large sample sizes makes a small differences (in absolute marks) significant as the variances are very small. 
Table 3: Residential status / Dunn-Sidak / Analysis of the differences between the categories with a confidence interval of $95 \%$

\begin{tabular}{lccccc}
\hline Contrast & Difference & Standardized difference & Critical value & Pr $>$ Diff & Significant \\
\hline Off-campus vs. On-Campus & 1.744 & 30.165 & 1.962 & $<0.0001$ & Yes \\
\hline Modified significance level: & & & 0.05 & &
\end{tabular}

\subsubsection{Race}

The marks according to the different races are as follows:

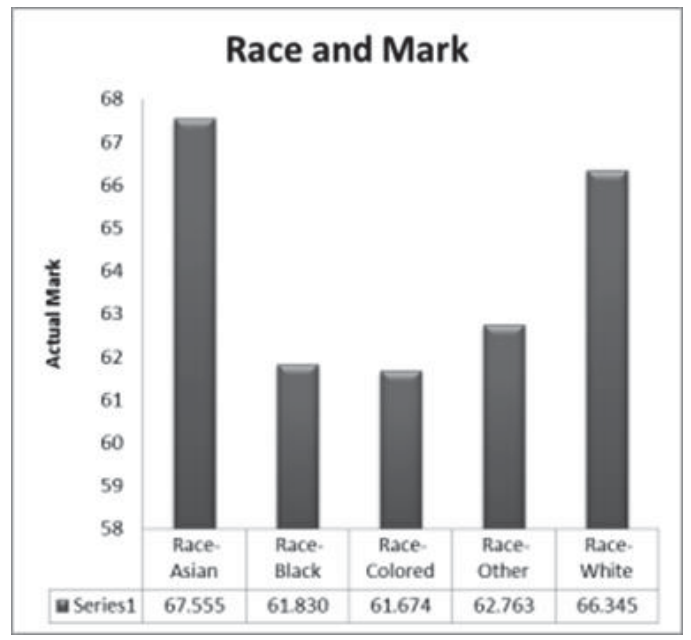

This shows that Asian students perform better than all other races followed by white students and the black and coloured students perform slightly lower than all the other categories.

Using the Fisher (LSD) Comparison test the following results are obtained:

Table 4: Race / Fisher (LSD) / Analysis of the differences between the categories with a confidence interval of $95 \%$

\begin{tabular}{lccccc}
\hline Contrast & Difference & Standardized difference & Critical value & Pr > Diff & Significant \\
\hline Asian vs. Colored & 5.845 & 2.159 & 1.962 & 0.031 & Yes \\
Asian vs. Black & 5.654 & 2.260 & 1.962 & 0.024 & Yes \\
Asian vs. Other & 5.292 & 1.725 & 1.962 & 0.085 & No \\
Asian vs. White & 1.200 & 0.479 & 1.962 & 0.632 & No \\
White vs. Colored & 4.645 & 3.962 & 1.962 & $<0.0001$ & Yes \\
White vs. Black & 4.454 & 8.067 & 1.962 & $<0.0001$ & Yes \\
White vs. Other & 4.092 & 2.200 & 1.962 & 0.028 & Yes \\
Other vs. Colored & 0.553 & 0.261 & 1.962 & 0.794 & No \\
Other vs. Black & 0.363 & 0.196 & 1.962 & 0.844 & No \\
Black vs. Colored & 0.191 & 0.166 & 1.962 & 0.868 & No \\
\hline
\end{tabular}

The pairwise comparison above shows that there are five racial groups which have significant differences in academic performance. The Black and White students have the biggest difference in performance followed by the Colored and White students. The difference between the performance of Asian students is significant when compared to Black and Colored students but non-significant elsewhere. The same is true for the white students against the Black, Colored and Other categories. This test shows us that the performance of Black students is comparable to Colored students but not with Asian and White students. Also, the test shows that White students perform better than all the other categories as their performance is only comparable to that of the Asian students. Though the Asian students have the highest marks the test reviews that their marks are comparable with the White category and also with the 'Other' category thus making the White category the only one with a unitary comparative. These differences can be attributed to the inherent real opportunities and freedoms the categories have, that is their capabilities. 


\subsection{Analysis of Variance (ANOVA)}

Running an analysis of variance type III to test for the strength of interactions among the significant background variables reveals that residential status when considered in a joint/mixed model has no effect on the student marks. The table below shows the summary.

Table 5: Mixed Models - Type III Sum of Squares analysis

\begin{tabular}{|c|c|c|c|c|c|c|c|}
\hline Source & Type & DF & Sum of squares & Mean squares & $\mathrm{E}$ (Mean squares) & $\mathbf{F}$ & $\operatorname{Pr}>\mathrm{F}$ \\
\hline Gender & Random & 1 & 1567.231 & 1567.231 & sigma2 + 1938.57 * sigma2(Gender) & 18.309 & $<0.0001$ \\
\hline Residential status & Random & 1 & 60.746 & 60.746 & 8.57 * sigma2(Res_status) & 0.710 & 0.400 \\
\hline Race & Random & 4 & 6040.696 & 1510.174 & sigma2 + 775.429 * sigma2( Race) & 17.643 & $<0.0001$ \\
\hline Error & & 1350 & 115556.958 & 85.598 & sigma2 & & \\
\hline
\end{tabular}

\subsection{Regression}

\subsubsection{The saturated model}

The ordinal least squares regression model was fitted on the data which was collected in the process outlined in the third section to ascertain which capabilities affect student marks.

The model form is:

$y_{i}=\beta_{o}+\beta_{1} x_{1, i}+\beta_{2} x_{2, i}+\cdots+\beta_{m} x_{m, i}+\varepsilon_{i} \ldots$ (iix)

Where:

$y_{i}$ is the mark of student $i$

$x_{p, i}$ is student i's indicator of capability $x_{p}$

$\beta_{0}$ is the student'smark which is independent of his measured capabilities.

$\beta_{i}$ is the coeffeficient or sensitivity of capability $i$ in the model

The regression results are as follows:

Table 6: Saturated regression model

\begin{tabular}{|l|c|c|c|c|}
\hline Variable & Coefficient & Std. Error & t-Statistic & Prob. \\
\hline C-constant & 38.13273 & 2.471135 & 15.43126 & 0 \\
\hline Affiliation & 0.085507 & 0.103165 & 0.82884 & 0.4073 \\
\hline Educational Resilience & 0.748266 & 0.109792 & 6.815303 & 0 \\
\hline Emotions & -0.077199 & 0.100843 & -0.765541 & 0.4441 \\
\hline Control over one's Environment & -0.088997 & 0.089168 & -0.998085 & 0.3184 \\
\hline Bodily Health & 0.184931 & 0.0811 & 2.280281 & 0.0227 \\
\hline Bodily Integrity & -0.082315 & 0.079425 & -1.036388 & 0.3002 \\
\hline Learning disposition: Language and confidence & 0.3739 & 0.080813 & 4.626739 & 0 \\
\hline Leisure & 0.006336 & 0.053346 & 0.118764 & 0.9055 \\
\hline Practical reason & -0.193325 & 0.101657 & -1.901738 & 0.0574 \\
\hline Senses and Imagination & 0.080288 & 0.100777 & 0.796687 & 0.4258 \\
\hline
\end{tabular}

The regression shows that there are three important capabilities at 95\% confidence level. These Capabilities include Bodily health, Educational Resilience, Learning disposition: Language and confidence. All three capabilities have positive co-efficiencies meaning they improve student marks.

At a more relaxed significance level of 10\%the capability practical reason also becomes significant. One interesting fact though is that the Practical reason has a negative coefficient. This implies that one possesses this capability their academic performance will slightly dampen. This could be because of the educational system which does not leave room for creativity and thorough pedagogical and epistemological contestations at undergraduate level.

\subsubsection{The reduced model}

The revised model at $10 \%$ level of significance would be: 
Average_Mark $_{i}=\beta_{o}+\beta_{1}$ Educational_resiliance $_{1, i}+\beta_{2}$ Learning_Disposition $_{2, i}+\beta_{3}$ Bodily_health $_{3, i}+$ $\beta_{4}$ Practical_reason $+\varepsilon_{i} \ldots$ (ix)

Running this model yields the following estimates:

Table 7: Final model

\begin{tabular}{|l|c|c|c|c|}
\hline & Coefficients & Standard Error & t Stat & P-value \\
\hline C & 38.31622 & 2.252066 & 17.01381 & $5.63 \mathrm{E}-59$ \\
\hline Educational Resilience & 0.743241 & 0.104194 & 7.133238 & $1.59 \mathrm{E}-12$ \\
\hline Bodily Health & 0.36063 & 0.076284 & 4.72746 & $2.51 \mathrm{E}-06$ \\
\hline Learning disposition: Language and confidence & 0.151803 & 0.075014 & 2.023655 & 0.043202 \\
\hline Practical Reason & -0.20156 & 0.092719 & -2.17391 & 0.029885 \\
\hline
\end{tabular}

Thus the shown capabilities are the most important capabilities in order to improve academic performance and they are summed up in the regression model below:

Average_Mark $_{i}=38.31622-0.202 *$ Practical_Reason $+0.743 *$ Educational Resilience $_{i}+0.152 *$ Learning_Disposition $_{i}+0.361 *$ Bodily_health $_{i}+\varepsilon_{i}$

All the coefficients to the selected capabilities, except practical reason due to the reason expressed above, have the expected positive sign. We therefore conclude that, in this population of University students, out of a total of 10 human capabilities consiredered, the following capabilities were found to be statistically significant and hence deemed critical for the wellbeing (academic achievement) of students, educational resilience, learning disposion, bodily health and practical reason. The model has a relatively low $R^{2}$ value indicating that there are many other factors besides the selected capabilities which affect the academic performance of students.

\section{Conclusion}

Academic achievement is affected by various factors. This paper has shown a few of the factors for instance gender, race, residential status, educational resistance, learning disposition and health and practical reason are critical for the wellbeing(academic achievent) of University Students. The last four of these factors have been identified and labelled as human Capabilities as shown in section 3. The first three factors which were termed background variables in this paper are in essence 'Functionings' as described by the Capabilities Approach. These differences can be attributed to the inherent real opportunities and freedoms the categories have, that is their capabilities. Student academic performance can therefore be analysed through the lenses of the Capabilities Approach by investigating student functionings and their capabilities. In essence, the Capabilities Approach alone is potent and robust enough to be used as a student welfare evaluative framework in higher education.

\section{References}

Addabbo, T., Tommaso, M. L. D. \& Facchinetti, G., 2004. To what extent fuzzy set theory and structural equation modelling can. Materiali di Discussione del Dipartimento di Economia Politica n.468.

Anand, P., Hunter, G. \& Smith, R., 2005b. Capabilities and well-being: evidence based on. Social Indicators Research, pp. 74:9-55..

Anon., 1964. Smooth Regression Analysis. The Indian Journal of Statistics, Series A (1961-2002) , Vol. 26, No. 4, pp. 359-372.

Barro, R. J. \& Lee, J.-W., 2001. International data on educational attainment: updates and implications. Oxford Economic Papers 3, pp. $541-563$

Basu, K., 1987. Achievements, capabilities and the concept of well-being. Social Choice and Welfare, pp. 4:69-76.

Berridge, K., 2000. The Psychology of Economic Decision. Volume 1: Rationality and wellbeing. New York: Oxford University Press.

Cheli, B. \& Lemmi, A., 1995. A totally fuzzy and relative approach to the multidimensional analysis of poverty. Economic Notes, 1, pp. 115-134.

Chiappero, M. E., 2000. A Multidimensional Assessment of WellbeingBased on Sen's Functioning appraoch. Rivista Internazionale di Scienze Sociali 108, pp. 207-39.

Comim, F., Qizibash, M. \& Alkire, S., 2008. The Capability Approach: Concepts, Measures and Applications. Cambridge : Cambridge University Press.

Dielman, T. E., 1991. Applied Regression Analysis for Business and Economics.. s.I.:PWS-KENT.

Ferrer-i-Carbonell, A. \& Friters, P., 2004. How important is methodology for the estimates of the determinants of happiness. Economic Journal, pp. 641-659.

Filippone, A., Cheli, B. \& D'Agostino, A., 2001. Adressing the interpretation and the. s.l.:University of Pisa. 
GUTTMAN, L., 1954. A new approach to factor analysis: the Radex. In: Mathematical thinking in the social sciences. New York : Free Press, pp. 258-3478.

Joreskog, K. G. \& Goldberger, A. S., 1975. Estimation of a Model with Multiple Indicators and Multiple Causes of a Single Latent Variable. Journal of the American Statistical Association, pp. 631-639.

LELLI, S., 2001. Factor Analysis vs. Fuzzy Sets Theory: Assessing the Influence of sen's functioning Approach. Leuven , s.n.

Lelli, S., 2001. Factor Analysis vs. . Fuzzy Sets Theory: Assessing the Influence of Different Techniques on Sen's Functioning Approach". Leuven, s.n.

Lovell K, R. S. T. P. w. L., 1994. Resources and functionings - a. In: Models and measurement of. Berlin : s.n., pp. 787-807.

Martinetti, E. C., 2000. A multidimensional assessment of well-being based on Sen's functioning approach. Rivista Internazionale di Scienze Sociali 58, pp. 207-239.

Nissani, M., 1997. Ten Cheers for Interdisciplinarity: The Case for Interdisciplinary Knowledge and Research. The Social Science Journal , 34(2), pp. 201-216.

Nussbaum, M., 2000. Women and Human Development. The Capabilities Approach.. Cambridge: Cambridge university Press.

P.Burnham, K. \& R.Anderson, D., 2002. Model selection and multimodel inference: a practical information-thoretic approach.. S.l.:Springer.

Qiziffar, M., 2008. Amarta Sen's capability view: insightful sketch or distorted picture? . In: Using the Capability Approach: prospctive and evaluative analyses. Cambridge: Cambridge University Press, p. 55.

Robeyns, I., 2012. THE CAPABILITY APPROACH IN PRACTICE. Human Development \& Capability Association, pp. 7-10.

Roemer, J., 1998. Equality of opportunity. Cambridge, Mass: Harvard University Press..

Schokkaert, E. \& Van Ootegem, L., 1990. Sen's concept of the living standard applied to. Recherches Economiques de Louvain 56(3-4):, pp. 429-450.

Seber, G. A. \& Lee, A. J., 2003. Linear Regression Analysis: Second Edition. New Jersey: John Wiley .

Sen, A., 1985a. Commodities and Capabilities. Holland: s.n.

Sen, A., 1985b. Well-being, Agency \& Freedom: The Dewey Lectures 1984. The Journal of Philosophy, pp. 169-121.

Sen, A., 1999. Development as Freedom. London: Oxford University Press.

Tsay, R. S., 2002. Analysis of Financial Time Series. New York: Wiley.

Von Altrock, C., 1997. Fuzzy logic and Neurofuzzy applications in Business. Prentice-Hall, Inc: s.n.

Walker, M., 2006. Higher Education Pedagogies. Berkshire,England: Society for Research into Higher Education \& Open University Press..

Wells, T., 2012. Internet Encyclopedia of Philosophy

White, S., 2010. Analysing wellbeing: a framework for. Development in Practice, Volume 20, Number 2.

Wildemuth, B. M., 1993. Post-Positivist Research: Two Examples of Methodological Pluralism. The Library Quarterly: Information, Community, Policy: Symposium on Qualitative Research: Theory, Methods, and Applications, 63(4), pp. 450-468.

Zadeh, L., 1965. Fuzzy sets. Information and Control. Vol 8, pp. 338-353.

Zellner, A., 1970. Estimation of Regression Relationships Containing Unobservable Variables. International Economic Review, 11, pp. 441-454. 